\title{
Turmeric extract inhibits apoptosis of hippocampal neurons of trimethyltin-exposed rats
}

\author{
Yuliani $\mathrm{S}^{1}$, Widyarini $\mathrm{S}^{2}$, Mustofa ${ }^{3}$, Partadiredja $\mathrm{G}^{4}$ \\ Faculty of Pharmacy, Ahmad Dahlan University, Yogyakarta, Indonesia. gpartadiredja@ugm.ac.id
}

\begin{abstract}
OBJECTIVES: The aim of the present study was to reveal the possible antiapoptotic effect of turmeric (Curcuma longa Linn.) on the hippocampal neurons of rats exposed to trimethyltin (TMT).

BACKGROUND: Oxidative damage in the hippocampus can induce the apoptosis of neurons associated with the pathogenesis of dementia

METHODS. The ethanolic turmeric extract and a citicoline (as positive control) solution were administered to the TMT-exposed rats for 28 days. The body weights of rats were recorded once a week. The hippocampal weights and imumunohistochemical expression of caspase 3 proteins in the CA1 and CA2-CA3 regions of the hippocampi were examined at the end of the experiment.

RESULTS: Immunohistochemical analysis showed that the injection of TMT increased the expression of caspase 3 in the CA1 and CA2-CA3 regions of hippocampus. TMT also decreased the body and hippocampal weights. Furthermore, the administration of $200 \mathrm{mg} / \mathrm{kg}$ bw dose of turmeric extract decreased the caspase 3 expression in the CA2-CA3 pyramidal neurons but not in the CA1 neurons. It also prevented the decrease of the body and hippocampal weights.

CONCLUSION: We suggest that the $200 \mathrm{mg} / \mathrm{kg}$ bw dose of turmeric extract may exert antiapoptotic effect on the hippocampal neurons of the TMT-exposed rats (Tab. 1, Fig. 3, Ref. 49). Text in PDF www.elis.sk. KEY WORDS: turmeric, hippocampus, trimethyltin, caspase 3, immunohistochemistry.
\end{abstract}

\section{Introduction}

The hippocampus is critically important to integrate and consolidate spatial memory (1). However, the hippocampus is sensitive to oxidative damage, which in turn induces cellular apoptosis or cell death. The cell death in the hippocampus has been reported to impair the memory functions of humans $(2)$, monkeys $(3,4)$, and rodents (5). In addition, the cell death caused by the oxidative stress in the CA1 (6) or CA3 (7) subregions of the hippocampus can cause synaptic disorders in these areas and contribute to the decline of memory function, which is the main symptom of dementia (8).

${ }^{1}$ Faculty of Pharmacy, Ahmad Dahlan University, Yogyakarta, Indonesia, ${ }^{2}$ Department of Pathology, Faculty of Veterinary Medicine, Universitas Gadjah Mada, Yogyakarta, Indonesia, ${ }^{3}$ Department of Pharmacology and Therapy, Faculty of Medicine, Universitas Gadjah Mada, Yogyakarta, Indonesia, and ${ }^{4}$ Department of Physiology, Faculty of Medicine, Universitas Gadjah Mada, Yogyakarta, Indonesia

Address for correspondence: G. Partadiredja, MD, MSc, PhD, Department of Physiology, Faculty of Medicine, Universitas Gadjah Mada, Yogyakarta 55281, Indonesia.

Phone: +62.274 .6492492$

Acknowlegement: The present study was a part of Sapto Yuliani's doctoral thesis and partially funded by a grant-in-aid of the Directorate of Higher Education, Ministry of Education and Culture, Indonesia (grant no. 011/ HB-LIT/III/2015). The authors would like to thank Agustin (Laboratory of Anatomy Pathology, Sardjito Hospital, Yogyakarta, Indonesia) for providing caspase 3 immunostaining.
Trimethyltin (TMT) is a neurotoxic organotin compound. Upon systemic administration of TMT, hippocampus is one of the primary targets of TMT-mediated neurotoxicity $(9,10)$. It is generally accepted that this neurotoxicity involves oxidative stress as the central pathogenesis $(11,12)$. TMT intoxication results in phenotypic changes indicative of apoptotic cell death, which includes chromatin condensation, nuclear fragmentation, mitochondrial dysfunction, reactive oxygen species production, membrane blebbing and caspase activation $(12,13)$. TMT activates protein kinase C (14) and induces apoptotic cascade (15). The apoptotic cascade implicates caspase 3 protein which plays an important role in the execution phase of the cascade $(9,16)$.

Curcuma longa Linn. of the Zingiberaceae family or turmeric is frequently used in Indian food as a spice, mainly as an ingredient in varieties of curry powders (17). It is also a well-known indigenous medicinal herb which has been used for centuries as a traditional medicine in several Asian countries. The yellow curcuminoid pigment of this herb has been reported to posses an antioxidative property. This antioxidant compound has been widely reported to exert neuroprotective effects via its action against oxidative stress. Previous studies reported that the administration of curcumin (the main compound of turmeric) decreased mitochondrial dysfunction (18) and prevented apoptosis in $\mathrm{AlCl}_{3}$-exposed rats model of dementia (19). Curcumin, therefore, could be considered as a promising therapeutic agent for the treatment of dementia. However, the popular use of curcumin in its pure form is still constrained 
by the impracticality of its mass production. Therefore turmeric extracts may be considered as a practical solution for the common and convenient consumption of curcumin. However, up to date there has been no study on the potential effect of turmeric extracts to prevent the apoptosis of hippocampal pyramidal neurons in rat models of dementia. In the present study, we investigated the effect of turmeric extracts on trimethyltin-induced cellular apoptosis of hippocampus in the rats. This effect was compared to that of citicoline, which is a medication commonly used for dementia.

\section{Materials and methods}

\section{Animals}

A total of 60 adult Sprague Dawley rats (180-200 g) obtained from the animal house of Universitas Gadjah Mada were used in the present experiment. The animals were placed individually in cages under standard conditions $\left(24-26{ }^{\circ} \mathrm{C}, 60-65 \%\right.$ humidity, natural 12/12 hour light/dark cycles) with ad libitum access to food and water. The rats were acclimatized for at least 6 days prior to the study. The experimental protocol and animal handling procedures were approved by the Ethics Committee of the Integrated Research and Testing Laboratory, Universitas Gadjah Mada (approval number 130/KEC-LPPT/XII/2013).

\section{Extraction of the turmeric rhizome}

The rhizomes of turmeric were purchased from CV. Merapi Farma, Yogyakarta, Indonesia, and authenticated by a botanist from the Faculty of Biology, Ahmad Dahlan University. The turmeric rhizome powder $(500 \mathrm{~g})$ was macerated twice in $96 \%$ ethanol (Merck, Germany), followed by filtration. The rhizome residue of this solvent was removed by filtration, and the resulting filtrate was concentrated under reduced pressure at $40^{\circ} \mathrm{C}$ in a rotary evaporator (Heidolph, Germany). The final yield of the turmeric extract was $30.38 \% \mathrm{w} / \mathrm{w}$. Then the concentration of curcumin which represented the major active content of the extract was measured using TLC scanner densitometer (CAMAG, Switzerland) operated at a wavelength of $426 \mathrm{~nm}$. The concentration of curcumin was 28.08 $\%$. The turmeric rhizome extract was eventually dissolved in the sodium carboxymethyl cellulose (CMC-Na) solution prior to oral administration to the rats.

\section{Experimental design}

The rats were subdivided into six groups as follows: The normal group $(\mathrm{N})$ was given per oral administration of $10 \mathrm{ml} / \mathrm{kg}$ bw CMC-Na solution and an intra-peritoneal injection of $0.9 \%$ saline, the control group (TMT) was given per oral administration of CMC-Na solution and an intra-peritoneal injection of TMT chloride (Sigma-Aldrich, Inc., St. Louis, USA) dissolved in $0.9 \%$ saline (20), the T-Cit group was given per oral administration of $200 \mathrm{mg} / \mathrm{kg}$ bw of citicoline (Bernofarm Pharmaceutical Company, Indonesia) and intra-peritoneal injection of TMT, and the T-E100, T-E200, and T-T300 groups were given per oral administration of $100 \mathrm{mg} / \mathrm{kg}$ bw, $200 \mathrm{mg} / \mathrm{kg}$ bw, and $300 \mathrm{mg} / \mathrm{kg}$ bw, of turmeric extract, respectivelly, as well as an intra-peritoneal injection of TMT. The oral treatments were carried out for 28 days, whereas the TMT chloride solution was injected as a single dose of $8 \mathrm{mg}$ / $\mathrm{kg}$ bw on day 8 of the treatments. The body weights of rats were recorded once a week.

\section{Tissue preparation}

On day 36 of the experiment, all rats were sacrificed by inhalation of $\mathrm{CO}_{2}$ and the cerebrums of the rats were carefully dissected out of their skulls. The right cerebral hemispheres of the rats were fixed in $10 \%$ buffered formaldehyde solution for 6 days. Afterwards, the hippocampi of these right cerebral hemispheres were removed from the brains, weighed, dehydrated in ethanol of graded concentrations, cleared with toluene, infiltrated with and eventually embedded in paraffin blocks. The paraffin blocks containing the hippocampal tissues were sectioned using a Reichert Wein microtome (Nr13137, Austria) at a nominal thickness of $3 \mu \mathrm{m}$.

\section{Immunohistochemical staining of caspase 3}

Each hippocampus was represented by one section, which was taken from the middle part of any given hippocampus. Sections of hippocampus were placed on poly-L-lysine slides in order to prepare for immunohistochemical staining. The immunohistochemical staining of caspase 3 was conducted according to manufacturer's procedure (Starr Trek Universal Detection System Protocol, Biocare Medical, Concord, California). The slides containing the hippocampal tissues were incubated at $45^{\circ} \mathrm{C}$ overnight. Afterwards, the sections were deparaffinised in a xylene solution (JT. Baker, USA) and rehydrated through alcohols with graded concentrations (JT. Baker, USA). They were incubated in $3 \% \mathrm{H}_{2} \mathrm{O}_{2}$ (JT. Baker, USA) for $15 \mathrm{~min}$ and rinsed in tap water. Antigen retrieval was conducted by immersing the sections in a citrate buffer solution (pH 6) at $95^{\circ} \mathrm{C}$ for $40 \mathrm{~min}$ in a decloacking chamber (Decloacking Chamber ${ }^{\mathrm{TM}}$ NXGEN, Biocare Medical, Concord, California). Then the sections were placed at a room temperature for $30 \mathrm{~min}$. Protein blocking was carried out on the sections using a background sniper (Biocare Medical, Concord, California) for 15 min. A primary antibody (Rabbit Polyclonal Anti-Caspase 3 Antibody, Lab Vision Co., USA) diluted at 1: 100 was applied on the sections. A section with no active caspase 3 expression was also prepared to serve as a negative control. The slides containing the sections were placed at a room temperature for $1 \mathrm{~h}$ and afterwards rinsed by PBS for 5 min. Trekkie Universal Link reagent (Biocare Medical, Concord, California, USA) containing biotinylated secondary antibody was applied on the sections and the sections were incubated at a room temperature for $20 \mathrm{~min}$. Trek Avidin-HRP (Biocare Medical, Concord, California, USA) was applied on the sections and subsequently the sections were rinsed using PBS. Betazoid DAB chromogen solution (Biocare Medical, Concord, California, USA) was dropped on the sections and the sections were left for $3 \mathrm{~min}$ at a room temperature. Hematoxylin staining was added for counter-staining. The sections were then dehydrated through ethanol with graded concentrations and cleared in xylene. Finally the sections were mounted on slides and cover-slipped. The number of apoptotic cells was determined by counting the number of apoptotic cells per three fields of view (x400 magnification), which were randomly chosen from each region of one section of each 
142-148

hippocampus. This examination was carried out blindly by the experimenter, therefore the experimenter was not aware to which group any given hippocampus belonged.

\section{Statistical analyses}

Body weights of rats were evaluated using a repeated measure analysis of variance (ANOVA) whereas the hippocampal weights and the number of caspase 3 expression were analyzed using a one-way ANOVA procedure. The differences between groups were analyzed using a post-hoc Tukey HSD test whenever necessary. The statistical analyses were done using SPSS software version 21 for Windows. The significance level was set at $\mathrm{p}<0.05$.

\section{Results}

\section{Body weights}

An overall observation on the subjects revealed that the rats injected with the TMT chloride showed more aggressive and hyperactive behavior than the rats injected with normal saline ( $\mathrm{N}$ group) after the TMT injection. Figure 1 shows that the body weights of all groups of rats increased during the five-week experimental period. The repeated measure ANOVA of these data showed that there was a significant main effect of groups $(p=0.048)$ but not the trials nor groups $x$ trials interaction. Post-hoc Tukey HSD test revealed that the body weights of the TMT group was significantly lower than that of the normal $(\mathrm{N})$ group $(\mathrm{p}=0.001)$. There were no significant differences in the body weights between the T-Cit and the $\mathrm{N}$ groups as well as between the three turmeric extracttreated groups and the $\mathrm{N}$ group.

\section{Hippocampal weights}

Figure 2 shows the average hippocampal weights of the six groups of rats. One-way ANOVA test of these data revealed a significant main effect of group $(p=0.0001)$. The post hoc Tukey HSD test showed that the mean hippocampal weights of the TMT group was significantly lower than that of the normal $(p=0.0001)$, T-Cit $(p=0.0001)$, T-E100 $(p=0.0001)$, T-E200 $(p=0.0001)$ and

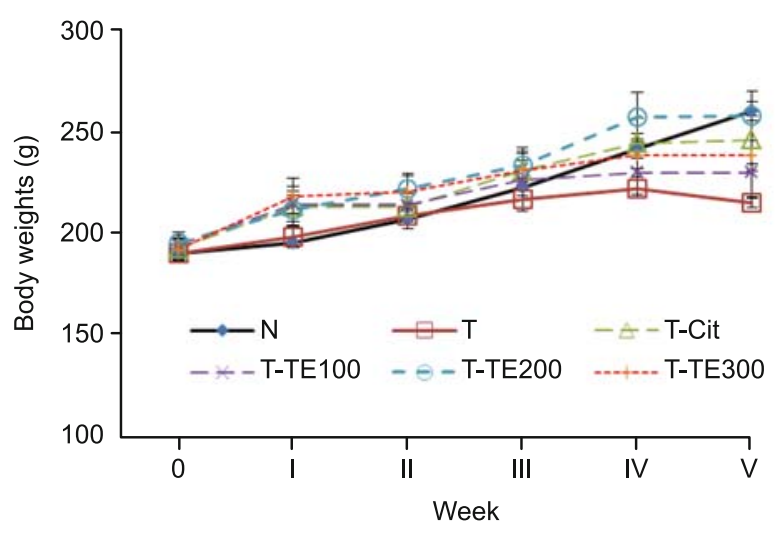

Fig. 1. Mean \pm SEM of the body weights of normal (N), TMT-injected, turmeric extract-treated, and citicoline-treated rats. Results of repeated measure ANOVA: $n=10 ; d f=5,54 ; F=0.908 ; p=0.048$.

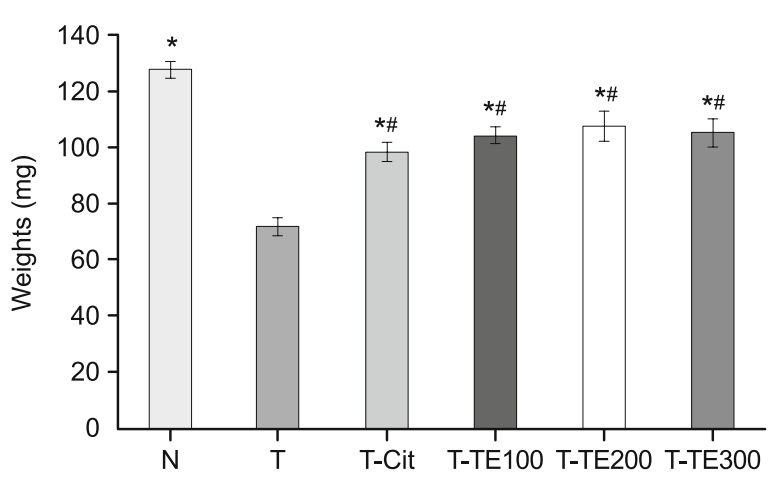

Fig. 2. Mean \pm SEM of the hippocampal weights of normal (N), TMTinjected, turmeric extract-treated, and citicoline-treated rats. Results of one-way ANOVA: $n=6$; $d f=5,30 ; F=14.197 ; p=0.0001,{ }^{*} p<$ 0.05 compared to the TMT group \& $\#$ p $<0.05$ compared to the normal group.

T-E300 groups $(\mathrm{p}=0.0001)$. The mean hippocampal weights of the T-Cit and the three turmeric extract-treated groups were also significantly lower than that of the $\mathrm{N}$ group $(\mathrm{p}=0.0001 ; \mathrm{p}=0.002$; $\mathrm{p}=0.006 ; \mathrm{p}=0.002$ respectively).

\section{Caspase 3 immunostaining}

The pro-apoptotic protein caspase 3 was expressed in the TMT-treated groups but not in the normal group. The antibodies specific for active caspases- 3 selectively stained the cytoplasms and nuclei of pyramidal cells in the CA2-CA3 regions and predominantly stained the cytoplasms of the pyramidal neurons in the CA1 regions (Fig. 3). Table 1 shows the data of the number of pyramidal neurons expressing caspase 3 per three fields of view in the CA1 and CA2-CA3 regions of hippocampus.

One-way ANOVA of the data of the number of pyramidal cells expressing caspase 3 per three fields of view in the CA1 region revealed a significant main effect of group $(p=0.001)$. Post-hoc Tukey HSD test of these data showed that the number of apoptotic cells in the CA1 region of the T group was significantly fewer than that of the $\mathrm{N}$ group $(\mathrm{p}=0.002)$, but was not different from that of the turmeric extract-treated and citicolin-treated groups.

One-way ANOVA of the data of the number of pyramidal cells expressing caspase 3 per three fields of view in the CA2-CA3 regions revealed a significant main effect of group $(p=0.002)$. Post-hoc Tukey HSD test of these data showed that the number of apoptotic cells in the CA2-CA3 region of the T-Cit and T-TE200 groups was significantly fewer than that of the $\mathrm{T}$ group $(\mathrm{p}=0.011$; $\mathrm{p}=0.008)(21)$.

\section{Discussion}

The present study has demonstrated that the TMT administration caused the increase of caspase 3 expression in the CA1 and CA2-CA3 regions as well as the decrease of the body and hippocampal weights. TMT-induced hyperactivity (22) may be one of the reasons for the decrease in body weight gain. Several studies have reported systemic manifestations of TMT intoxication, 
CA1
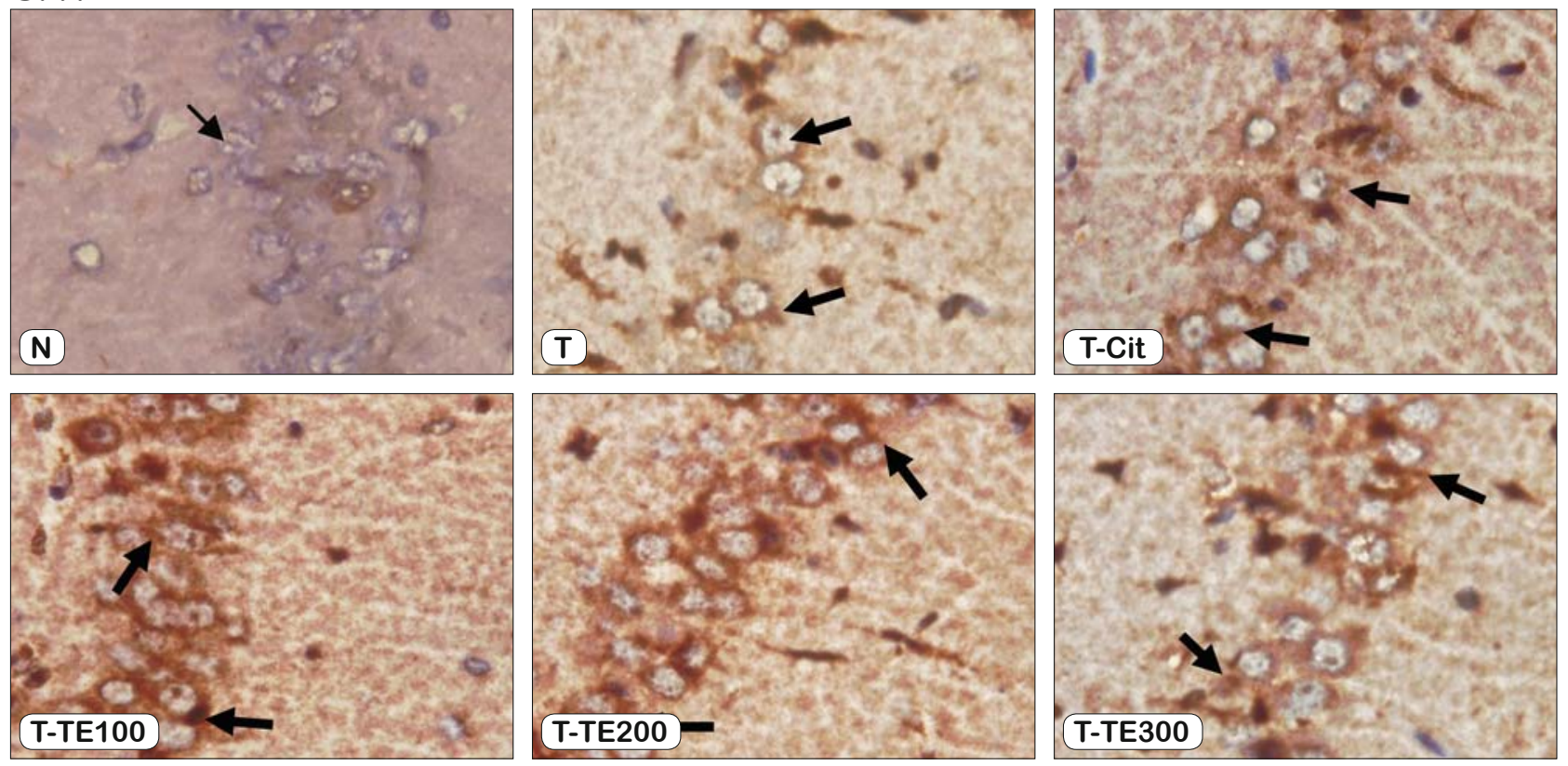

\section{CA2-CA3}
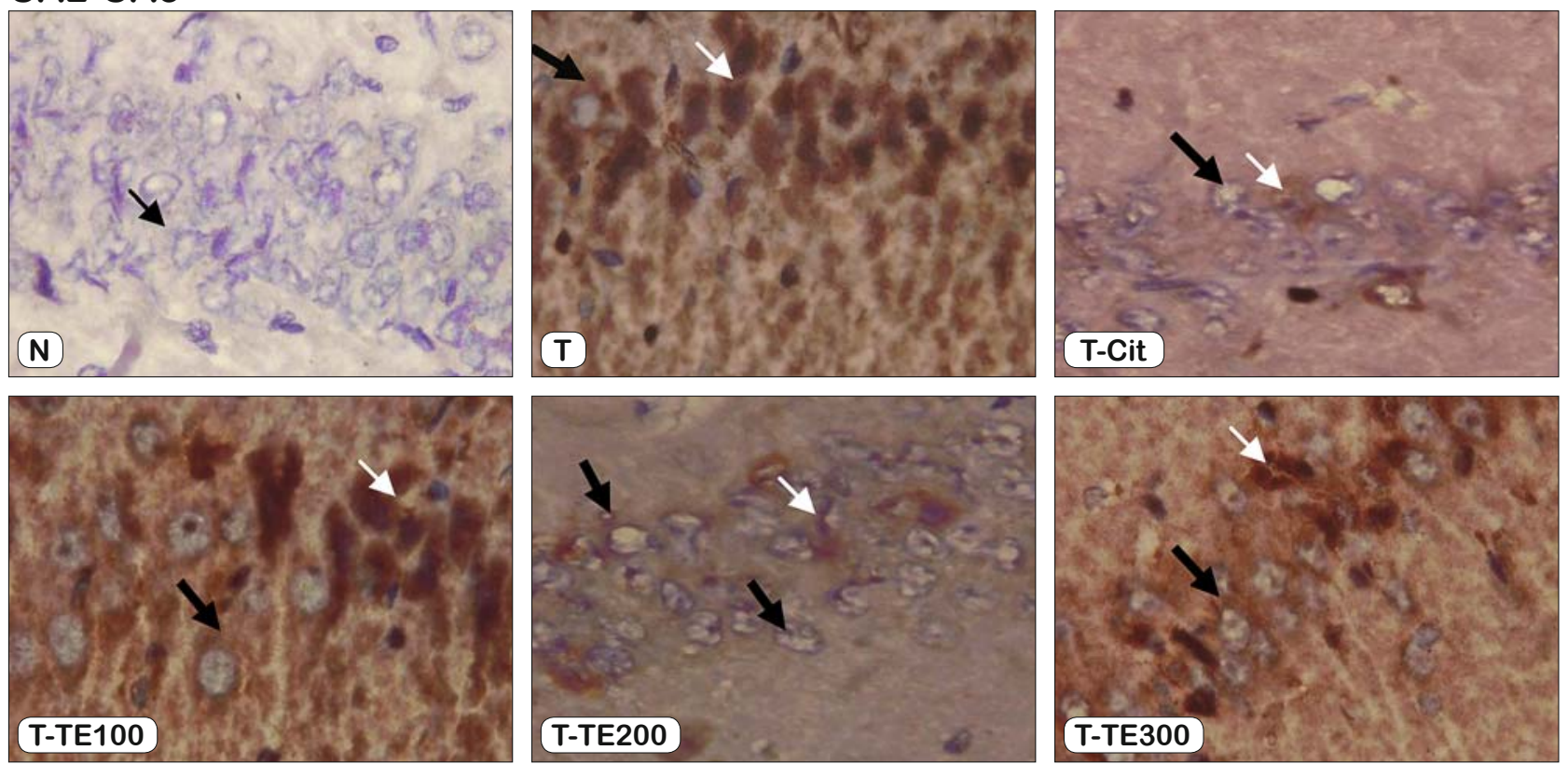

Fig. 3. Neuropathological changes in the hippocampi of rats exposed with TMT as indicated by caspase-3 imunohystochemical staining. In the TMT treated groups caspase-3 immunostaining is present in the nuclei (white arrows) and cytoplams (thick black arrows) of pyramidal cells of CA2-CA3 regions and is predominantly present in the cytoplasms of pyramidal cells of CA1 regions. Normal cells are pointed with thin black arrows.

which include the damage of the epithelial cells in the proximal renal tubule that led to the increase of urine $\mathrm{pH}$ and diuresis $(23$, 24). TMT also impairs the immune system and causes atrophy of the spleen $(25,26)$. All of these intoxication effects likely caused the body weight loss of the rats in the present study.

TMT is known to cause the neural degeneration and behavioral changes (27). Rodents exposed to TMT may suffer from disori- entation, convulsions, and aggressive behavior. Such effects may appear due to the loss of septal structures and the extensive destruction of neurons in the amygdala and hippocampus $(28,29)$. In rats, TMT induces the degeneration of pyramidal neurons in the hippocampus and cortical areas, including pyriform cortex, entorhinal cortex, and subiculum, that are connected to the hippocampus $(27,30)$. This TMT-induced damage is thought to be 
Tab. 1. The number (mean \pm SEM) of pyramidal neurons expressing caspase 3 per three fields of view in the CA1 and CA2-CA3 regions of hippocampus of rats.

\begin{tabular}{llcc}
\hline Groups & $\mathrm{n}$ & CA1 region & CA2-CA3 region \\
\hline $\mathrm{N}$ & 6 & $5.33 \pm 1.73^{\mathrm{a}}$ & $4.66 \pm 1.21^{\mathrm{a}}$ \\
$\mathrm{T}$ & 6 & $28.33 \pm 2.68$ & $30 \pm 2.82$ \\
T-Cit & 6 & $21.50 \pm 5.16^{\mathrm{b}}$ & $15 \pm 1.82^{\mathrm{a}}$ \\
T-TE100 & 6 & $22.33 \pm 3.05^{\mathrm{b}}$ & $24 \pm 4.72^{\mathrm{b}}$ \\
T-TE200 & 6 & $24.66 \pm 3.32^{\mathrm{b}}$ & $12 \pm 1.35^{\mathrm{a}}$ \\
T-TE300 & 6 & $25.33 \pm 2.71^{\mathrm{b}}$ & $28 \pm 3.34^{\mathrm{b}}$ \\
\hline
\end{tabular}

ip = intra-peritoneal; po = per oral; $\mathrm{N}=10 \mathrm{ml} / \mathrm{kg}$ bw CMC-Na solution (po) $+0.9 \%$ $\mathrm{NaCl}$ (ip); $\mathrm{T}=10 \mathrm{ml} / \mathrm{kg}$ bw CMC-Na solution (po) $+8 \mathrm{mg} / \mathrm{kg}$ bw TMT chloride (ip); $\mathrm{T}$ $\mathrm{Cit}=200 \mathrm{mg} / \mathrm{kg}$ bw Citicolin $+8 \mathrm{mg} / \mathrm{kg}$ bw TMT chloride (ip); T-TE $100=100 \mathrm{mg} / \mathrm{kg}$ bw turmeric extract (po) $+8 \mathrm{mg} / \mathrm{kg}$ bw TMT chloride (ip); T-TE200 $=200 \mathrm{mg} / \mathrm{kg}$ bw turmeric extract (po) $+8 \mathrm{mg} / \mathrm{kg}$ bw TMT chloride (ip); T-TE300 $=300 \mathrm{mg} / \mathrm{kg}$ bw turmeric extract (po) $+8 \mathrm{mg} / \mathrm{kg}$ bw TMT chloride (ip). ${ }^{\text {a }} \mathrm{p}<0.05$, compared with $\mathrm{T}$ group, ${ }^{\mathrm{b}} \mathrm{p}<0.05$, compared with $\mathrm{N}$ group. Results of one-way ANOVA for CA1 region: $\mathrm{df}=5,30 ; \mathrm{F}=8.967 ; \mathrm{p}=0.001$. Results of one-way ANOVA for CA2-CA3 region: $\mathrm{df}=5,30 ; \mathrm{F}=10.207 ; \mathrm{p}=0.002$

associated with oxidative stress, calcium overload, and mitochondrial damage. It seems that the mitochondrial damage is mediated by stannin (SNN) protein, which is a protein with 88 amino acids encoded by the cDNA of TMT-sensitive cells (15). SNN can be found in the hippocampus, neocortex, cerebellum, striatum, midbrain, and kidney (31). It possibly lies in the outer membrane of mitochondria (32) and the membrane of the endoplasmic reticulum (33). SNN directly binds with dimethyltin (demethylation results of TMT) and causes the release of cytochrome $\mathrm{c}$ and the activation of caspases. The activation of the caspase (cysteine-aspartic acid protease) family is considered to mediate the apoptosis of neurons (13) which is characterized with the expression of caspase 3 (34). This caspase group of enzymes plays a key role in the execution phase of an apoptosis cascade. Caspase 3 is required for DNA fragmentation and morphological change associated with apoptosis (35). It is plausible that the decrease of the number of the hippocampal cells due to apoptosis might have contributed to the hippocampal weight loss in the present study.

In the present study, the caspase 3 protein expression occurred predominantly in the cytoplasm of the pyramidal cells in the CA1 region, while it appeared both in the nuclei and cytoplasm of the pyramidal neurons in the CA2-CA3 region. This difference was likely due to the differential vulnerability towards neurotoxicants between cells of these two regions (6). The neurons in the CA1 region contains more NMDA receptors (NMDARs) than those in the CA3 region $(36,37)$. Therefore, the activation of NMDARs due to oxidative stress results in the increase of $\mathrm{Ca}^{2+}$ levels more in the CA1 neurons than in the CA3 neurons $(6,38)$. The increase of $\mathrm{Ca}^{2+}$ levels gives rise to glutamate excitotoxicity that finally causes cellular apoptosis $(39,40)$ that is more prevalent in the $\mathrm{CA} 1$ region than in the $\mathrm{CA} 2-\mathrm{CA} 3$ region.

The present study has shown that the $200 \mathrm{mg} / \mathrm{kg}$ bw dose of turmeric extract may inhibit the apoptosis of the pyramidal neurons in the CA2-CA3 region but not in the CA1 region. The number of neurons expressing caspase 3 in the CA2-CA3 region in the $\mathrm{T}$ group was the most numerous, whereas that in the T-TE200 group was the fewest amongst the extract treated-groups. A number of studies has demonstrated the antioxidant and neuroprotective potential of turmeric in various experimental models of neurodegeneration (41-44). An administration of curcumin for 2 months significantly reduced the ischemia-induced neuronal death as well as glial activation (45). Curcumin administration also decreased lipid peroxidation, mitochondrial dysfunction, and apoptotic indices. Mitochondria play a crucial role in electron transports and oxidative phosphorylation. A decline in mitochondrial membrane potential (MMP), a release of cytochrome $\mathrm{c}$ from mitochondria to cytosol, an alteration in the ratio of Bax-Bcl-2 and an activation of subsequent caspase cascade are the key signaling mechanism that takes part in the mitochondrial-dependent apoptotic pathway. Curcumin effectively attenuates all of these alterations and suppresses mitochondrial-dependent apoptotic pathway (46). Curcumin also efficiently restores DNA from damage and protects the cells from apoptosis via its antiapoptotic activity.

The rats treated with $200 \mathrm{mg} / \mathrm{kg}$ bw of turmeric extract showed similar caspase 3 expression to the rats treated with $200 \mathrm{mg} / \mathrm{kg}$ bw of citicoline. Citidine-5-diphosphocholine or citicoline (CDPcholine) is commonly used as a neuroprotective and memoryenhancing drug in Alzheimer's disease. Non-clinical studies also have demonstrated the neuroprotective effects of CDP-choline in ischemic animal models. In a gerbil forebrain ischemia model, the application of CDP-choline increased the number of surviving cells in the hippocampal CA1 region (47). Citicolin also decreased the number of caspase 3 positive cells and prevented the fragmentation of the DNA in the penumbra zone of the brains of rats with cerebral artery occlusion (48).

In conclusion, our present study shows that the $200 \mathrm{mg} / \mathrm{kg}$ bw dose of turmeric extract may exert antiapoptotic effects on the hippocampal neurons of the TMT-exposed rats. Further studies are warranted to explore the potentials of this extract for preventing dementia.

\section{Learning points}

- TMT exposure induces neurotoxicity in the hippocampal neurons of rats

- The neurotoxicity results in the increase of caspase 3 expression of hippocampal neurons involved in apoptotic cell death

- The antioxidant and neuroprotective potential of $200 \mathrm{mg} / \mathrm{kg}$ bw of turmeric extract may inhibit the apoptosis of hippocampal neurons

\section{References}

1. Bird CM, Burgess N. The hippocampus and memory: insights from spatial processing. Nat Rev Neurosci 2008; 9: 182-194.

2. Manns JR, Hopkins RO, Reed JM, Kitchener EG, Squire LR. Recognition memory and the human hippocampus. Neuron 2003; 37: 171-180.

3. Nemanic S, Alvarado MC, Bachevalier J. The hippocampal/parahippocampal regions and recognition memory: insights from visual paired comparison versus object-delayed nonmatching in monkeys. J Neurosci J Soc Neurosci 2004; 24: 2013-2026.

4. Zola SM, Squire LR, Teng E, Stefanacci L, Buffalo EA, Clark RE. Impaired recognition memory in monkeys after damage limited to the hippocampal region. J Neurosci J Soc Neurosci 2000; 20: 451-463. 
5. Prusky GT, Douglas RM, Nelson L, Shabanpoor A, Sutherland RJ. Visual memory task for rats reveals an essential role for hippocampus and perirhinal cortex. Proc Natl Acad Sci U S A 2004; 101: 5064-5068.

6. Wang X, Michaelis EK. Selective Neuronal Vulnerability to Oxidative Stress in the Brain. Front Aging Neurosci 2010; 2.

7. Kumar A. Long-Term Potentiation at CA3-CA1 Hippocampal Synapses with Special Emphasis on Aging, Disease, and Stress. Front Aging Neurosci 2011; 3 .

8. Fukui M, Choi HJ, Zhu BT. Rapid generation of mitochondrial superoxide induces mitochondrion-dependent but caspase independent cell death in hippocampal neuronal cells that morphologically resembles necroptosis. Toxicol Appl Pharmacol 2012; 262: 156-166.

9. Geloso MC, Corvino V, Michetti F. Trimethyltin-induced hippocampal degeneration as a tool to investigate neurodegenerative processes. Neurochem Int 2011; 58: 729-738.

10. Ogita K, Nishiyama N, Sugiyama C, Higuchi K, Yoneyama M, Yoneda Y. Regeneration of granule neurons after lesioning of hippocampal dentate gyrus: evaluation using adult mice treated with trimethyltin chloride as a model. J Neurosci Res 2005; 82: 609-21.

11. Gunasekar P, Li L, Prabhakaran K, Eybl V, Borowitz JL, Isom GE. Mechanisms of the apoptotic and necrotic actions of trimethyltin in cerebellar granule cells. Toxicol Sci Off J Soc Toxicol 2001; 64: 83-89.

12. Jenkins SM, Barone Jr. S. The neurotoxicant trimethyltin induces apoptosis via caspase activation, $\mathrm{p} 38$ protein kinase, and oxidative stress in PC12 cells. Toxicol Lett 2004; 147: 63-72.

13. Geloso MC, Vercelli A, Corvino V, Repici M, Boca M, Haglid K et al. Cyclooxygenase 2 and caspase 3 expression in trimethyltin-induced apoptosis in the mouse hippocampus. Exp Neurol 2002; 175: 152-160.

14. Shin E-J, Nam Y, Tu T-HT, Lim YK, Wie M-B, Kim D-J et al. Protein kinase $\mathrm{C} \delta$ mediates trimethyltin-induced neurotoxicity in mice in vivo via inhibition of glutathione defense mechanism. Arch Toxicol 2015.

15. Buck-Koehntop BA, Mascioni A, Buffy JJ, Veglia G. Structure, dynamics, and membrane topology of stannin: a mediator of neuronal cell apoptosis induced by trimethyltin chloride. J Mol Biol 2005; 354: 652-665.

16. Kassed CA, Butler TL, Navidomskis MT, Gordon MN, Morgan D, Pennypacker KR. Mice expressing human mutant presenilin-1 exhibit decreased activation of NF-kappaB p50 in hippocampal neurons after injury. Brain Res Mol Brain Res 2003; 110: 152-157.

17. Ishrat T, Hoda MN, Khan MB, Yousuf S, Ahmad M, Khan MM et al. Amelioration of cognitive deficits and neurodegeneration by curcumin in rat model of sporadic dementia of Alzheimer's type (SDAT). Eur Neuropsychopharmacol J Eur Coll Neuropsychopharmacol 2009; 19: 636-647.

18. Wang Q, Sun AY, Simonyi A, Jensen MD, Shelat PB, Rottinghaus GE et al. Neuroprotective mechanisms of curcumin against cerebral ischemia-induced neuronal apoptosis and behavioral deficits. J Neurosci Res 2005; 82: 138-148.

19. Pan R, Qiu S, Lu D, Dong J. Curcumin improves learning and memory ability and its neuroprotective mechanism in mice. Chin Med J (Engl) 2008; 121: 832-839.

20. Park H-J, Shim HS, Choi WK, Kim KS, Shim I. Neuroprotective Effect of Lucium chinense Fruit on Trimethyltin-Induced Learning and Memory Deficits in the Rats. Exp Neurobiol 2011; 20: 137-143.

21. Yuliani S. The Effect of Curcumin Standardized Turmeric Extract on Trimethyltin Induced-Dementia Model of Rat. UGM, 2015.
22. Earley B, Burke M, Leonard BE. Behavioural, biochemical and histological effects of trimethyltin (TMT) induced brain damage in the rat. Neurochem Int 1992; 21: 351-366.

23. Ren X, Wu X, Sui G, Gong Z, Yawson E, Wu B et al. Chronic trimethyltin chloride exposure and the development of kidney stones in rats. J Appl Toxicol JAT 2015; 35: 500-507.

24. Tang X, Yang X, Lai G, Guo J, Xia L, Wu B et al. Mechanism underlying hypokalemia induced by trimethyltin chloride: Inhibition of $\mathrm{H}+/ \mathrm{K}+$-ATPase in renal intercalated cells. Toxicology 2010; 271: 45-50.

25. Hioe KM, Jones JM. Effects of trimethyltin on the immune system of rats. Toxicol Lett 1984; 20: 317-323.

26. Snoeij NJ, van Iersel AA, Penninks AH, Seinen W. Toxicity of triorganotin compounds: comparative in vivo studies with a series of trialkyltin compounds and triphenyltin chloride in male rats. Toxicol Appl Pharmacol 1985; 81: 274-826.

27. Balaban CD, Callaghan JPO, Billingsle ML. Trimethyltin-induced neuronal damage in the rat brain: comparative studies using silver degeneration stains, immunocytochemistry and immunoassay for neuronotypic and gliotypic proteins. Neuroscience 1988; 26: 337-361.

28. Boyer IJ. Toxicity of dibutyltin, tributyltin and other organotin compounds to humans and to experimental animals. Toxicology 1989; 55 : 253-298.

29. Dyer RS. Physiological methods for assessment of Trimethyltin exposure. Neurobehav Toxicol Teratol 1982; 4: 659-64.

30. Koczyk D. How does trimethyltin affect the brain: facts and hypotheses. Acta Neurobiol Exp (Warsz) 1996; 56: 587-596.

31. Dejneka NS, Polavarapu R, Deng X, Martin-DeLeon PA, Billingsley ML. Chromosomal localization and characterization of the stannin (Snn) gene. Mamm Genome Off J Int Mamm Genome Soc 1998; 9: 556-564.

32. Billingsley ML, Yun J, Reese BE, Davidson CE, Buck-Koehntop BA, Veglia G. Functional and structural properties of stannin: roles in cellular growth, selective toxicity, and mitochondrial responses to injury. J Cell Biochem 2006; 98: 243-250.

33. Davidson CE, Reese BE, Billingsley ML, Yun JK. Stannin, a protein that localizes to the mitochondria and sensitizes NIH-3T3 cells to trimethyltin and dimethyltin toxicity. Mol Pharmacol 2004; 66: 855-863.

34. Hyman BT, Yuan J. Apoptotic and non-apoptotic roles of caspases in neuronal physiology and pathophysiology. Nat Rev Neurosci 2012; 13: 395-406.

35. Eldadah BA, Faden AI. Caspase pathways, neuronal apoptosis, and CNS injury. J Neurotrauma 2000; 17: 811-829.

36. Fiacco TA, Rosene DL, Galler JR, Blatt GJ. Increased density of hippocampal kainate receptors but normal density of NMDA and AMPA receptors in a rat model of prenatal protein malnutrition. J Comp Neurol 2003; 456: 350-360.

37. Korbo L, Ladefoged O, Lam HR, Ostergaard G, West MJ, ArlienSøborg P. Neuronal loss in hippocampus in rats exposed to toluene. Neurotoxicology 1996; 17: 359-366.

38. Haxaire C, Turpin FR, Potier B, Kervern M, Sinet P-M, Barbanel G et al. Reversal of age-related oxidative stress prevents hippocampal synaptic plasticity deficits by protecting D-serine-dependent NMDA receptor activation. Aging Cell 2012; 11: 336-344.

39. Lu Y, Wang R, Cicha M, Chapleau M, Abboud F. Transient acidosis induces a preconditioning chloride conductance that protects mouse no- 


\section{2-148}

dose neurons from NMDA-induced apoptosis (1132.13). FASEB J 2014; 28: $1132-1113$.

\section{Quincozes-Santos A, Bobermin LD, Tramontina AC, Wartchow} KM, Tagliari B, Souza DO et al. Oxidative stress mediated by NMDA, AMPA/KA channels in acute hippocampal slices: neuroprotective effect of resveratrol. Toxicol Vitro Int J Publ Assoc BIBRA 2014; 28: 544-551.

41. Bala K, Tripathy BC, Sharma D. Neuroprotective and anti-ageing effects of curcumin in aged rat brain regions. Biogerontology 2006; 7: 81-89.

42. Bishnoi M, Chopra K, Kulkarni SK. Protective effect of Curcumin, the active principle of turmeric (Curcuma longa) in haloperidol-induced orofacial dyskinesia and associated behavioural, biochemical and neurochemical changes in rat brain. Pharmacol Biochem Behav 2008; 88: $511-522$.

43. Dohare P, Garg P, Jain V, Nath C, Ray M. Dose dependence and therapeutic window for the neuroprotective effects of curcumin in thromboembolic model of rat. Behav Brain Res 2008; 193: 289-297.

44. Kuhad A, Chopra K. Curcumin attenuates diabetic encephalopathy in rats: behavioral and biochemical evidences. Eur J Pharmacol 2007; 576: 34-42.
45. Wu J, Li Q, Wang X, Yu S, Li L, Wu X et al. Neuroprotection by curcumin in ischemic brain injury involves the Akt/Nrf2 pathway. PloS One 2013; 8: e59843.

46. Rashid K, Sil PC. Curcumin enhances recovery of pancreatic islets from cellular stress induced inflammation and apoptosis in diabetic rats. Toxicol Appl Pharmacol 2015; 282: 297-310.

47. Takasaki K, Uchida K, Fujikawa R, Nogami A, Nakamura K, Kawasaki $C$ et al. Neuroprotective effects of citidine-5-diphosphocholine on impaired spatial memory in a rat model of cerebrovascular dementia. J Pharmacol Sci 2011; 116: 232-237.

48. Krupinski J, Ferrer I, Barrachina M, Secades JJ, Mercadal J, Lozano R. CDP-choline reduces pro-caspase and cleaved caspase 3 expression, nuclear DNA fragmentation, and specific PARP-cleaved products of caspase activation following middle cerebral artery occlusion in the rat. Neuropharmacology 2002; 42: 846-854.

Received November 22, 2016. Accepted November 29, 2016. 